\title{
Mechanism of Material Removal in Nanomachining of Fused Quartz using AFM Diamond Tip"
}

\author{
Yoshio ICHIDA ${ }^{* *}$, Takashi YAMAGUCHI ${ }^{* *}$ and Makoto SASANUMA ${ }^{* *}$ \\ ** Department of Mechanical and Intelligent Engineering, Utsunomiya University \\ 7-1-2, Yoto, Utsunomiya, 321-8585, Japan \\ E-mail: ichida@cc.utsunomiya-u.ac.jp
}

\begin{abstract}
Nanometer-scale machining experiments on fused quartz surfaces have been performed using an atomic force microscope combined with a two-axis capacitive force/displacement transducer. The minimum normal force $f_{n P}$ required to reproducibly form a groove was about $4.7 \mu \mathrm{N}$. The minimum critical normal force $f_{n R}$, tangential force $f_{t R}$ and groove depth $d_{g R}$ when the material removal process began were found to be $33.7 \mu \mathrm{N}, 18.7 \mu \mathrm{N}$, and $4.3 \mathrm{~nm}$, respectively. Changes in the swelling ratio $R_{s}$ and the ratio of force components at the critical normal force $f_{n R}$ can be used to detect a critical condition when the material deformation behavior changes from plastic deformation to material removal.
\end{abstract}

Key words: Nanomachining, Atomic Force Microscope, Nanometer-scale Groove, Fused Quartz

\section{Introduction}

In recent years, surface modification with a scanning probe microscope has attracted special interest as a nanomachining technique for processing surfaces on a nanometer scale $^{(1-4)}$. In particular, nanometer-scale processing using an atomic force microscope (AFM) will play an increasingly important role in ultrafine fabrication for manufacturing electronic or micromechanical devices ${ }^{(5-8)}$. In order to enhance the utilization of this technique, it is essential to clarify the processing mechanism and characteristics ${ }^{(9-11)}$.

The objective of this study is to clarify the mechanisms of material removal in nanomachining using an AFM diamond tip. A series of nanomachining experiments on polished quartz surfaces has been conducted using an AFM combined with a two-axis capacitive force/displacement transducer to investigate the critical conditions required to initiate the material removal process, such as the minimum normal force, tangential force, and groove depth when the material removal process begins.

\section{Experimental Procedure}

Figure 1 shows the basic experimental model to clarify the material removal mechanism in nanomachining. The straight nanometer-scale groove was processed using the AFM diamond tip as a tool. The straight grooves were processed under a constant normal machining force $f_{n}$ and a constant machining speed $v_{m}$. The minute tangential machining force $f_{t}$ was measured experimentally, and was used to analyze the material removal mechanism in nanomachining.

A series of nanomachining experiments on fused quartz was performed using an AFM combined with a two-axis capacitive force/displacement transducer, a schematic illustration

${ }^{*}$ Received 16 Feb., 2010 (No. 10-0086) [DOI: 10.1299/jamdsm.4.1015]

Copyright $(2010$ by JSME 


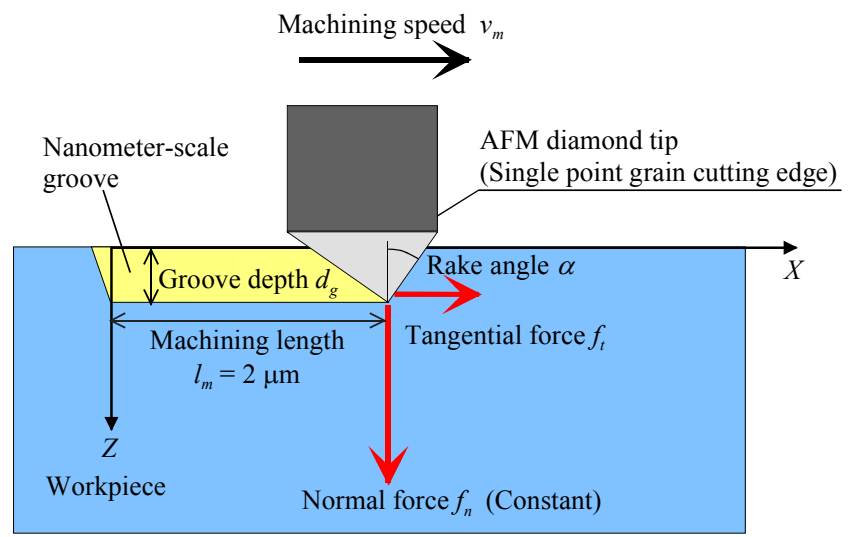

Fig.1 Experiment model for constant-force nanomachining with AFM diamond tip

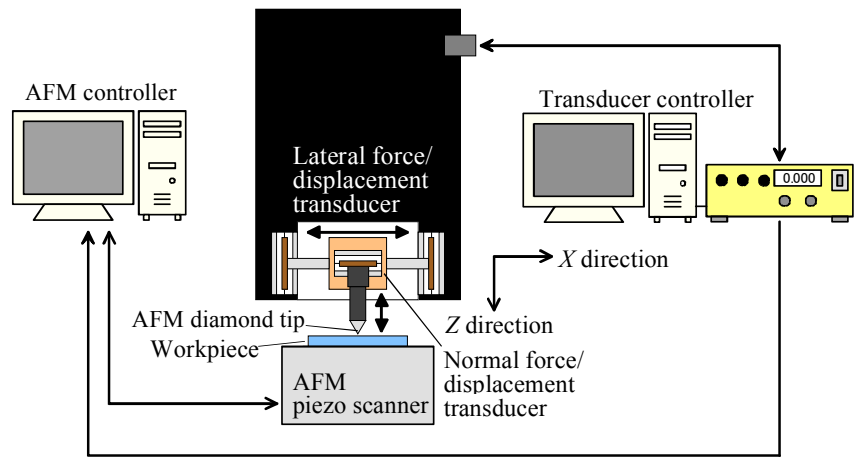

Fig.2 Schematic illustration of constant-force nanomachining equipment with AFM

of which is shown in Fig.2. The $X$-axis transducer (lateral force transducer) was composed of two additional sensors that were mounted transversely to the $Z$-axis force transducer (normal force transducer). The two-axis transducer applied and measured force and displacement in both the $Z$ and $X$-axis.

A three-sided pyramidal diamond tip (cube corner tip) with a radius of $50 \mathrm{~nm}$ set in the center of the $Z$-axis force transducer, was used for both nanomachining and imaging in these experiments. Figure 3 shows the shape of the diamond tip, the SEM image of its top edge, and the machining direction used for processing straight grooves in this study.

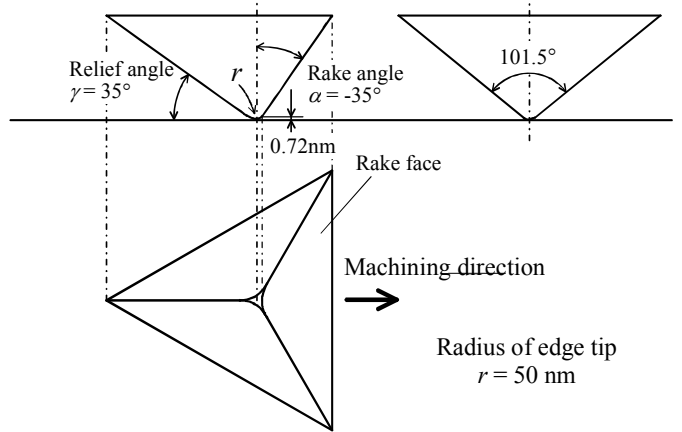

(a) Shape of diamond tip

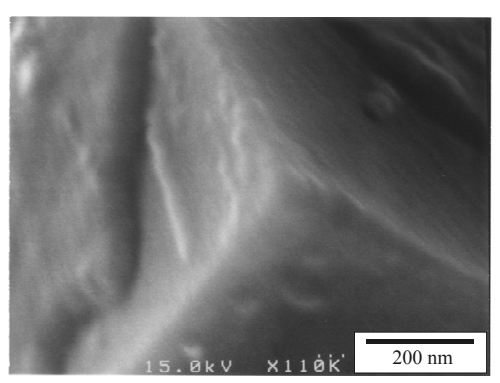

(b) SEM image of diamond tip

Fig.3 Dimensions of AFM tip and its SEM image 
Experimental conditions for processing straight grooves are shown in Table 1. After the nanomachining experiments, the modified surface was immediately imaged at a normal force of about $0.5 \mu \mathrm{N}$ using the same diamond tip.

Table 1 Machining conditions.

\begin{tabular}{ll|l}
\hline Machining tool & & $\begin{array}{l}\text { Three-sided pyramidal diamond tip } \\
\text { Tip edge radius: } 50 \mathrm{~nm} \\
\text { Rake angle: }-35^{\circ} \\
\text { Relief angle: } 35^{\circ}\end{array}$ \\
\hline Machining length $\quad l_{m}$ & $2 \mu \mathrm{m}$ \\
\hline Machining speed $\quad v_{m}$ & $100 \mathrm{~nm} / \mathrm{s}$ \\
\hline Nominal normal force & $F_{n}$ & $1,2,4,6,8,10,20,30,40,50,60$, \\
& & $70,80,90,100 \quad \mu \mathrm{N}$ \\
\hline Workpiece & & Fused quartz \\
& & Nanohardness: $8.7 \mathrm{GPa}$ \\
& & Elastic modulus: $72 \mathrm{GPa}$ \\
& Surface roughness: $0.5 \mathrm{~nm} R a$ \\
\hline Atmosphere & In air \\
& Temperature: $22^{\circ} \mathrm{C}$ \\
& Humidity: $50 \%$ \\
\hline
\end{tabular}

\section{Experimental Results and Discussion}

\subsection{AFM and SEM Observations of Nanometer-Scale Material Removal Process}

Figure 4 shows typical AFM images of the straight grooves with a length of $2 \mu \mathrm{m}$ processed at various nominal normal forces $F_{n}$ of $50 \mu \mathrm{N}$ or less. In this figure, the actual normal machining force $f_{n}$ measured with the $Z$-axis force transducer, the $\mathrm{A}-\mathrm{A}^{\prime}$ sectional

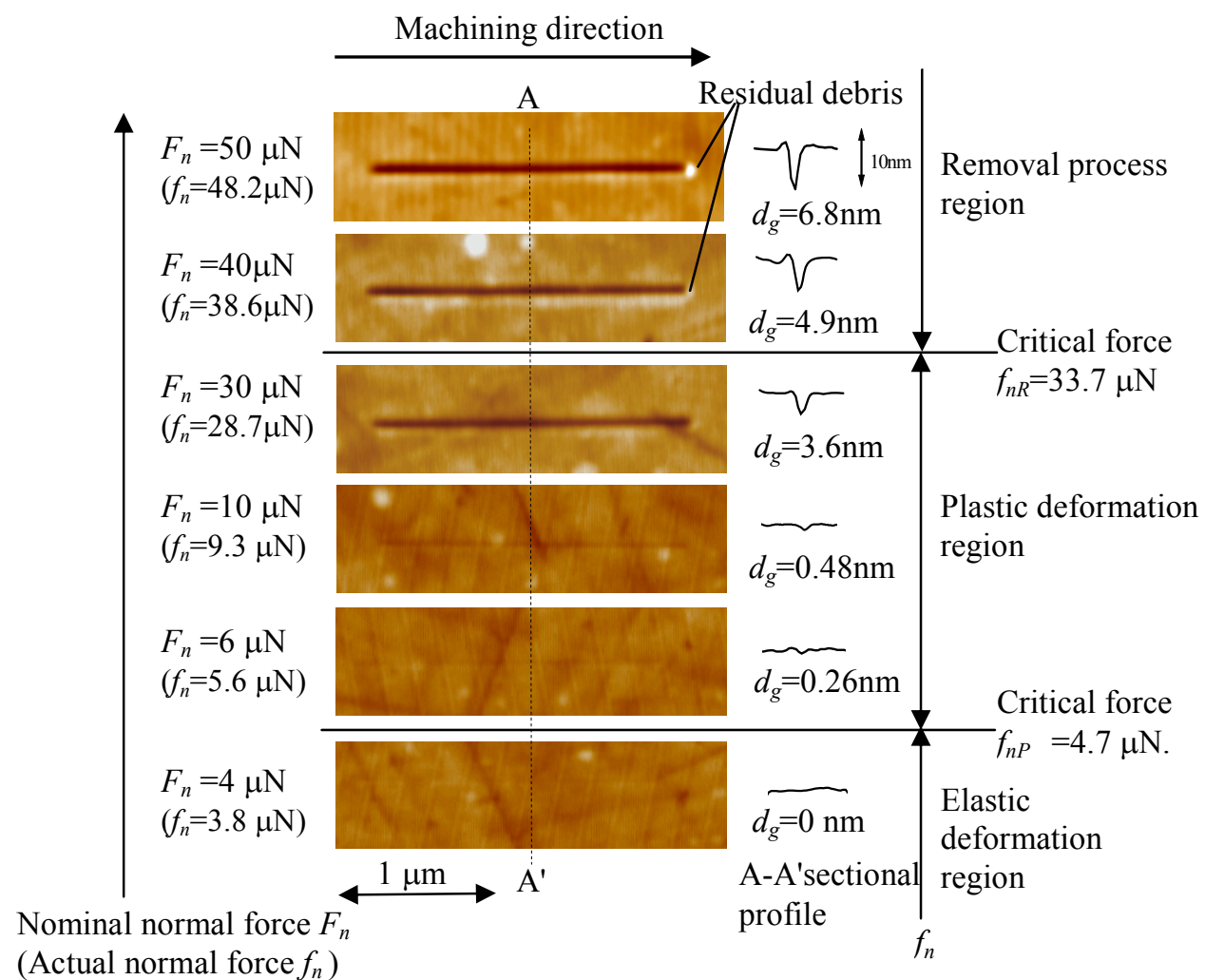

Fig.4 Typical AFM observation results of nanometer-scale grooves formed under constant normal forces $F_{n}=4,6,10,30,40$ and $50 \mu \mathrm{N}$ 
profiles of grooves, and the actual mean groove depths $d_{g}$ obtained from these profiles are also indicated. Grooves were not formed using machining normal forces of $4 \mu \mathrm{N}$ or less. However, at a nominal normal force of $6 \mu \mathrm{N}$ a very fine straight groove with a constant depth of about $0.26 \mathrm{~nm}$ and a constant width of about $20 \mathrm{~nm}$ was successfully processed, as shown in this figure. This result shows that the minimum normal force required to reproducibly form a groove on the fused quartz surface is between 4 and $6 \mu \mathrm{N}$. This minimum force is a critical value (denoted by $f_{n P}$ ) when the plastic deformation begins in this nanomachining. The value of $f_{n P}$ is given by $4.7 \mu \mathrm{N}$ that is the mean value of 5.6 and $3.8 \mu \mathrm{N}$.

Both depth and width of the straight groove increased with increases of the normal force. In particular, when the normal force exceeded $30 \mu \mathrm{N}$, small amounts of residual debris can be observed at the end of the groove. This residual debris seems to offer evidence that material removal action occurred. In particular, when the AFM probe scanned the groove surface, the cutting chip that remained in the end of the groove was crushed by the probe. As a result, it seems that such residual debris remained in the end of the groove. In general, it is easy for the residual cutting chip to be crushed by the probe in scanning for imaging because it projects from the surface. Therefore, it is very difficult to observe with the AFM the cutting debris that remained after nanomachining.

We then attempted to observe the cutting debris with a scanning electron microscope (FE-SEM). The typical observation results are shown in Fig.5. When the normal force was $30 \mu \mathrm{N}$ or less, no cutting chips were observed. However, when the normal force was $40 \mu \mathrm{N}$, a nanometer-scale cutting chip that remained in the end of the groove was observed. From these results, it is confirmed that the minimum normal force when the chip begins to be produced on the fused quartz surface is between 30 and $40 \mu \mathrm{N}$. Figure 6 shows the high magnification SEM images of the cutting chips obtained at the normal forces of 40 and 50 $\mu \mathrm{N}$. Because these cutting chips have a continuous shape and a smooth surface, they may be judged to be a flow-type chip. These results show that the mechanism of the groove

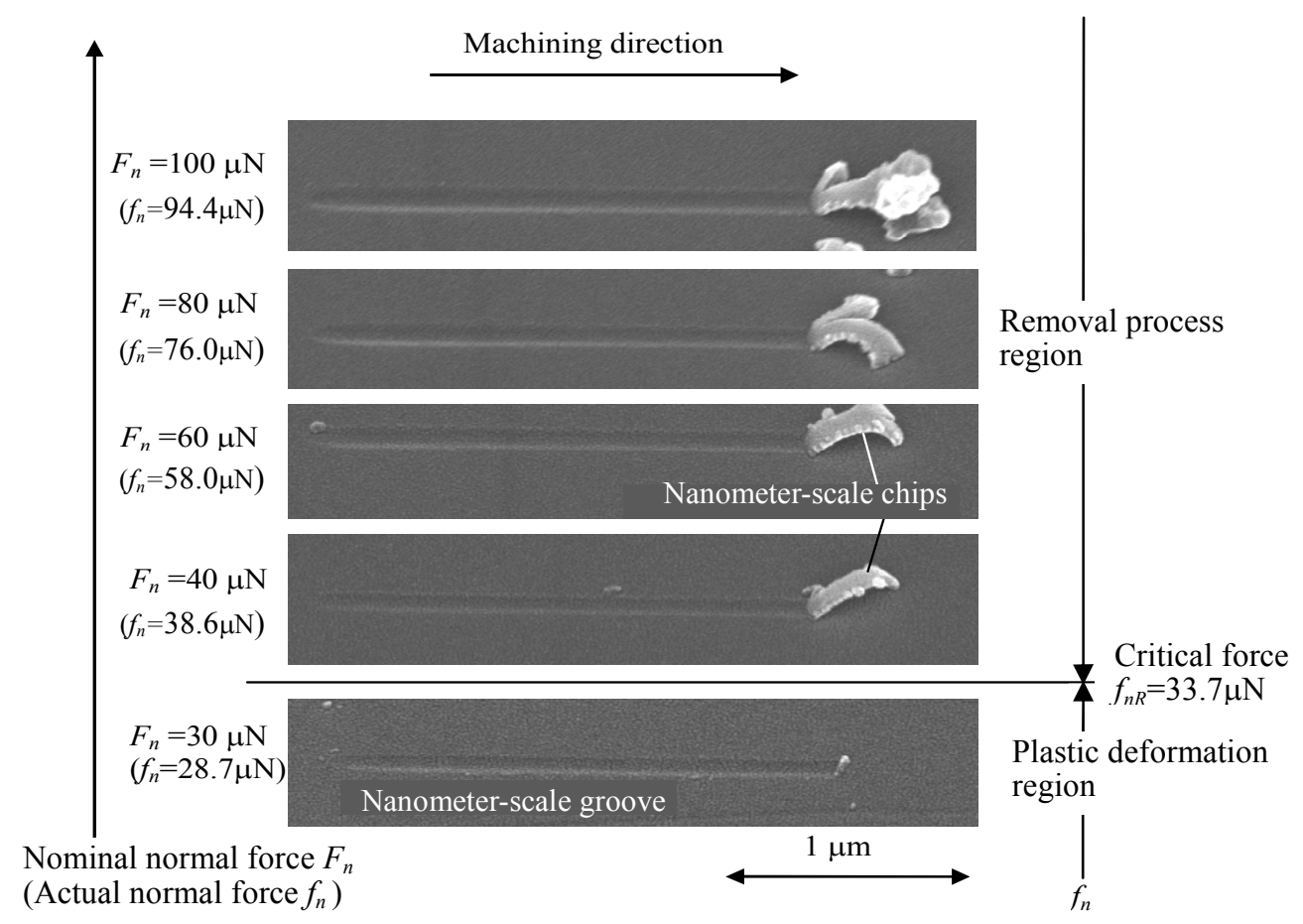

Fig.5 Typical SEM observation results of nanometer-scale grooves and the cutting chips processed under constant normal forces $F_{n}=30,40,60,80$ and $100 \mu \mathrm{N}$ 


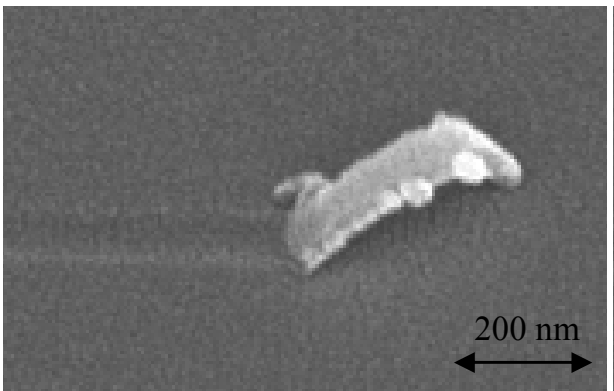

(a) $F_{n}=40 \mu \mathrm{N}\left(f_{n}=38.6 \mu \mathrm{N}\right)$

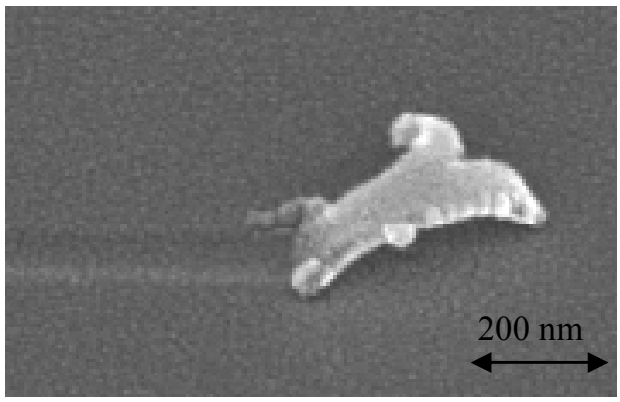

(b) $F_{n}=50 \mu \mathrm{N}\left(f_{n}=48.2 \mu \mathrm{N}\right)$

Fig.6 High magnification SEM images of cutting chips

formation, that is, the material removal in nanomachining, is based on the ductile mode minute cutting action that is chiefly performed by the shear deformation. The size of the cutting chip increases with increasing normal force.

On the basis of these AFM and SEM observations, it is confirmed that the minimum groove depth when the material removal process begins is between 3.6 and $4.9 \mathrm{~nm}$. This minimum groove depth $d_{g R}$ is an important critical value to indicate the machining unit in this nanomachining process, and is given by $4.3 \mathrm{~nm}$ as a mean value of the upper and lower bound values ( 4.9 and $3.6 \mathrm{~nm}$, respectively). At the same time, it is confirmed that the minimum normal force to initiate material removal is between 28.7 and $38.6 \mu \mathrm{N}$. The minimum force $f_{n R}$ is also an important critical value to characterize the machining unit, and is given by $33.7 \mu \mathrm{N}$ (the mean of the upper bound value of 38.6 and the lower bound value of $28.7 \mu \mathrm{N})$.

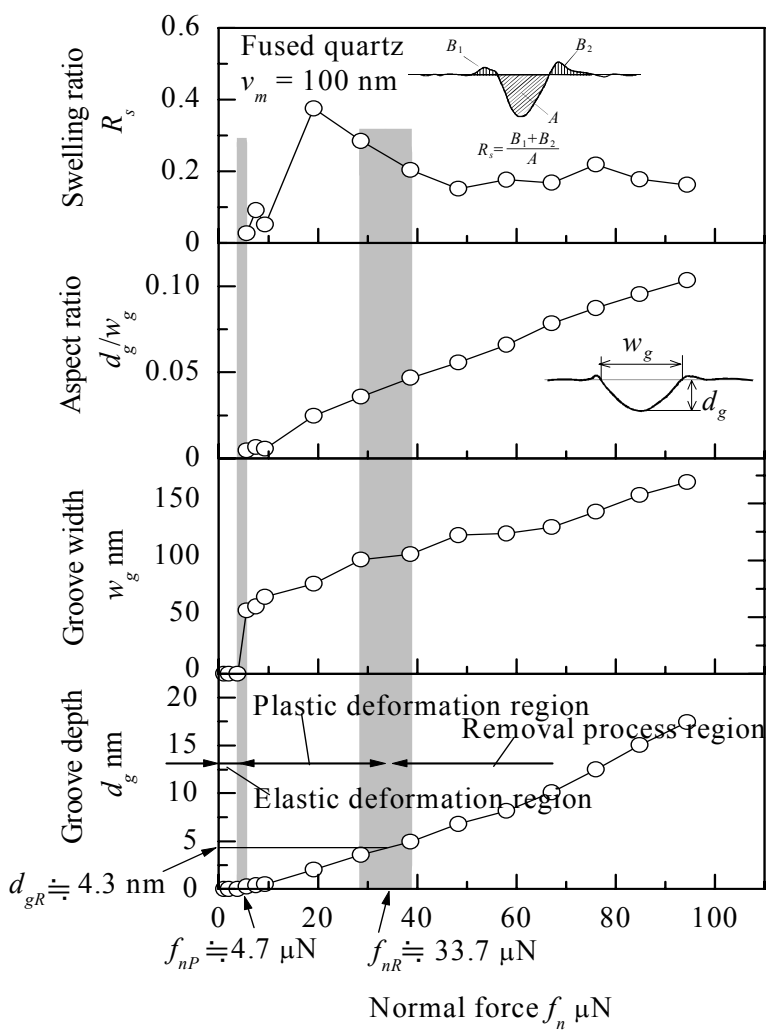

Fig.7 Changes of tangential force and ratio of force components with increasing normal force $f_{n}$. 


\subsection{Transient Behavior from Plastic Deformation to Removal Processes}

Figure 7 shows the effects of the normal force on the characteristic machining parameters that indicate the features of the groove processed by a diamond edge, that is, the groove depth $d_{g}$, groove width $w_{g}$, the aspect ratio $d_{g}, w_{g}$, and swelling ratio $R_{s}$. These results indicate that the following three regions exist in the process until the fused quartz surface is removed by the diamond edge.

These regions are

(A) Elastic deformation region $0 \leq f_{n} \leq 4.7 \mu \mathrm{N}$

(B) Elastic/plastic deformation region $4.7 \leq f_{n} \leq 33.7 \mu \mathrm{N}$

(C) Removal process region $33.7 \leq f_{n}\left(d_{g} \geq 4.3 \mathrm{~nm}\right)$.

As shown in Figure 7, the swelling ratio $R_{s}$ decreases rapidly when the normal force exceeds the critical value $f_{n R}$. This feature change in $R_{s}$ can be used to detect a transitional condition when the material behavior changes from plastic deformation to the removal process.

Figure 8 shows the changes of tangential force $f_{t}$ and ratio of force components with increasing normal force $f_{n}$. This result shows that the minimum tangential force, that is, the critical value $f_{t P}$ when the plastic deformation begins, is given by $2.2 \mu \mathrm{N}$ as a mean value of the upper and lower bounds (2.46 and $1.96 \mu \mathrm{N}$, respectively). At the same time, the mean minimum tangential force $f_{t R}$ when the material removal process begins is $18.7 \mu \mathrm{N}$ (the mean value of the upper bound, $22.8 \mu \mathrm{N}$, and lower bound, $14.5 \mu \mathrm{N}$ ).

An important feature in Figure 8 is the change in the ratio of the force components with an increase in the normal force $f_{n}$. In particular, the value of $f_{t} / f_{n}$ changes suddenly from a rapid increase to a gradual increase with increases in the normal force. This feature change in $f_{t} / f_{n}$ is caused by the difference in the direction of the processing force between the plastic

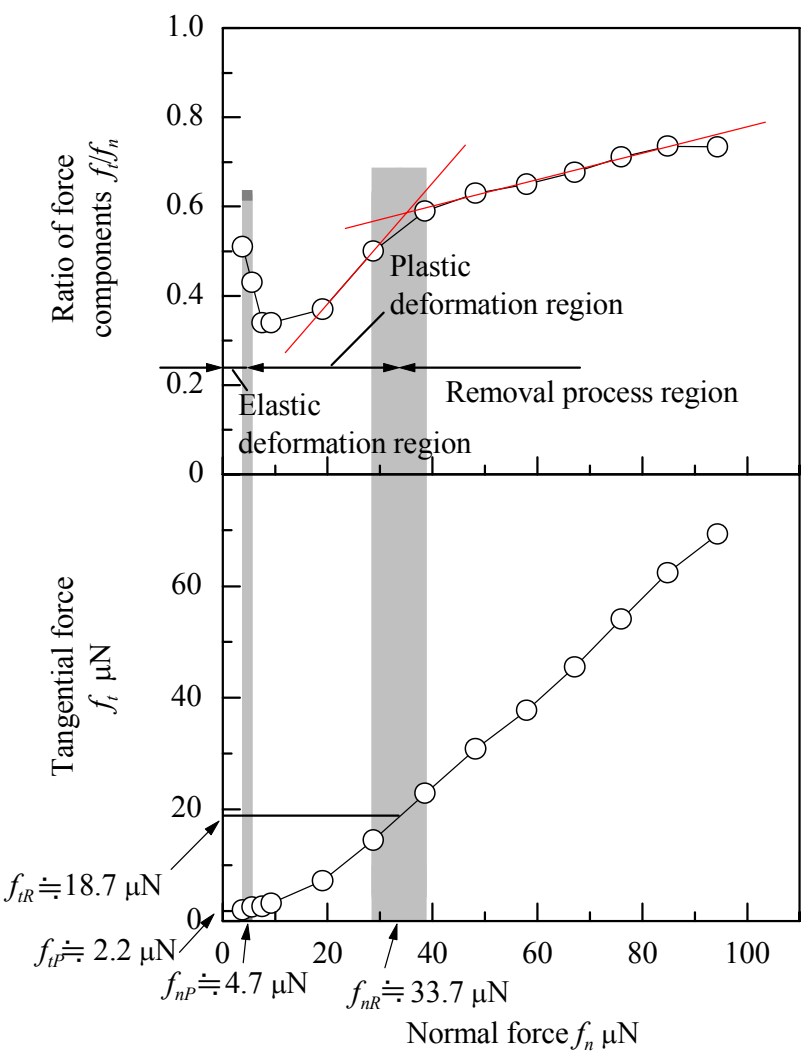

Fig.8 Changes of tangential force and ratio of force components with increasing normal force $f_{n}$. 
deformation and removal process regions [11]. This phenomenon can be also used to detect a transitional condition when the material deformation behavior changes from the plastic deformation to the removal process.

\section{Conclusion}

Nanometer-scale machining on fused quartz surfaces has been carried out with an AFM combined with a two-axis capacitive force/displacement transducer. The main results obtained within the range of experimental conditions in this study are:

(1) The minimum normal force $f_{n P}$ required to reproducibly form a groove is about $4.7 \mu \mathrm{N}$.

(2) The minimum critical normal force $f_{n R}$, tangential force $f_{t R}$, and groove depth $d_{g R}$ required to initiate the material removal process are $33.7 \mu \mathrm{N}, 18.7 \mu \mathrm{N}$ and $4.3 \mathrm{~nm}$, respectively.

(3) The change in the swelling ratio $R_{s}$ and the ratio of force components $f_{t} / f_{n}$ at the critical normal force $f_{n R}$ can be used to detect a critical condition when the material deformation behavior changes from plastic deformation to material removal.

(4) The mechanism of the groove formation, that is, the material removal in nanomachining, is based on the ductile mode minute cutting action that is chiefly performed by the shear deformation.

\section{References}

(1) Snow, E. S. and Campbell, P. M., Fabrication of Si Nanostructures with an Atomic Force Microscope, Applied Physics Letters, Vol.64, No.15 (1993), pp.1932-1934.

(2) Tsau, L., Wang, D. and Wang, K. L., Nanometer Scale Patterning of Silicon (100) Surfaces by an Atomic Force Microscope Operating in Air, Applied Physics Letters, Vol.64, No.16 (1994), pp. 2133- 2135.

(3) Wendel, M., Kühn, S., Lorenz, H. and Kotthaus, J. P., Nanolithography with an Atomic Force Microscope for Integrated Fabrication of Quantum Electronic Devices, Applied Physics Letters, Vol.65, No.14 (1994), pp.1775-1777.

(4) Bhushan, B. and Koinkar, V. N., Nanoindentation Hardness Measurements using Atomic Force Microscopy, Applied Physics, Vol.64, No.13 (1994), pp.1653-1655.

(5) Samitsu, Y., A Study of Atomic Scale Processing using an Atomic Force Microscope, Journal of Japan Society for Precision Engineering, 1995, Vol.61, No.8 (1995), pp.1121-1125.

(6) Tegen, S., Kracke, B., and Damaschke, B., Surface Modifications with a Scanning Force Microscope, Review of Scientific Instruments, Vol.63, (1997), pp.1458-1464.

(7) Li, S. F. Y., Ng, H. T., Zhang, P. C., Ho, P. K. H., Zhou, L., Bao, G. W. and Chan, S. L. H., Submicrometer Lithography of a Silicon Substrate by Machining of Photoresist using Atomic Force Microscopy Followed by Wet Chemical Etching, Nanotechnology, Vol.8, (1997), pp.76-81.

(8) Miyazaki, T., Yoshioka, S., Shirai, Y., Misu, T. and Taniguchi, N., 1998, Removal Characteristics of Processing with SPM, Annals of the CIRP, 1998, Vol.47, No.1 (1998), pp.153-156.

(9) Ichida, Y., Sato, R., Morimoto, Y. and Takahashi, K., Nanometer-Scale Machining of Single-Crystal Silicon using an Atomic Force Microscope, JSPE Publication Series, No.3 (1999), pp.677-682.

(10) Ichida, Y., Morimoto, Y., and Sato, R., Nanoscale Mechanical Processing of Silicon (001) Surface by Atomic Force Microscope Diamond Tip, Proceedings of the $1^{\text {st }}$ euspen Topical Conference on Fabrication and Metrology in Nanotechnology, Vol.1, (2000), pp.206-210.

(11) Ichida, Y., Morimoto, Y., Sato, R. and Murakami, M., Nanomachining on Si (100) Surface using an Atomic Force Microscope with a Lateral Force Transducer, Technical Proceedings of the 2003 Nanotechnology Conference, Vol.1, (2003), pp. 534-537. 